\title{
Osteoporosis-pseudoglioma syndrome in South Africa
}

\author{
M Chetty, ${ }^{1,2,3}$ BChD, MChD, PhD candidate; L X G Stephen, ${ }^{1,2}$ BChD, PhD; T Roberts, ${ }^{1,2,3}$ BChD, MChD, PhD candidate \\ ${ }^{1}$ Faculty of Dentistry, University of the Western Cape, Cape Town, South Africa \\ ${ }^{2}$ University of Western Cape/University of Cape Town Dental Genetic Clinic; and Red Cross Children's War Memorial Hospital, Cape Town, South Africa \\ ${ }^{3}$ Division of Human Genetics, Department of Pathology, Faculty of Health Sciences, University of Cape Town, South Africa
}

\section{Corresponding author: M Chetty (drmchetty@mweb.co.za)}

\begin{abstract}
The osteoporosis-pseudoglioma syndrome (MIM 259770) is a rare autosomal recessive disorder in which bone fragility and frequent fractures are associated with serious ocular changes. The skeletal manifestations resemble those of osteogenesis imperfecta while hyperplasia of the vitreous, eye and corneal opacities often mimics the appearance of intraocular glioma. This disorder was previously reported in a South African family of Indian stock as 'the ocular form of osteogenesis imperfecta. Terminological discussion followed and it was suggested that these individuals had osteoporosis-pseudoglioma syndrome. This article describes and depicts the manifestations of the disorder and discusses the nosology.
\end{abstract}

S Afr Med J 2016;106(6):S100-S102. DOI:10.7196/SAMJ.2016.v106i6.11008

\section{Statement of clinical relevance}

In osteoporosis-pseudoglioma syndrome (OPPG), skeletal fragility predisposes to frequent fracturing with consequent physical handicap, while the ocular complications result in defective vision or blindness. OPPG has serious clinical consequences and since several South African (SA) Indians have a common geographical origin, it is possible that the determinant gene exists with significant frequency in this population. For this reason, the authors hope to bring this extremely rare disorder to the attention of the SA medical community.

\section{Background}

OPPG (MIM 259770) is a rare autosomal recessive condition that is characterised by severe osteoporosis and eye abnormalities leading to loss of vision. Affected persons present with multiple fractures, and the skeletal manifestations closely resemble those of osteogenesis imperfecta (OI), while hyperplasia of the vitreous, and eye and corneal opacities can mimic an intraocular glioma. These manifestations are progressive, and affected individuals may have considerable physical handicap and visual disturbance.

In 1985, an SA Indian family, in which 4 brothers and 2 sisters had severe osteoporosis and blindness, were reported on in an article: 'The ocular form of osteogenesis imperfecta. ${ }^{\left[{ }^{[1]}\right.}$ It was subsequently suggested that this was actually OPPG and this diagnosis was acknowledged by the authors. ${ }^{[2]}$

\section{Methods}

All investigations were undertaken with full ethical approval in accordance with the
Declaration of Helsinki as updated in the version promulgated in June 2013, and the Singapore Statement on Research Integrity.

During the clinical investigations of individuals with thin bone disorders as a component of a $\mathrm{PhD}$ thesis registered in the Division of Human Genetics at the University of Cape Town, two persons with a confirmed diagnosis of OPPG were identified. They were the nephew (SB) and his uncle $(\mathrm{BB})$, who were the only surviving affected members of the family described in $1985 .^{[1]}$ In addition, two SA females (HB and BA) of Indian descent were identified with osteoporosis and ocular problems of unknown origin. All four individuals had a common ancestral origin from the state of Gujarat in India.

\section{Family background of SB and BB}

The progenitors of the affected persons arrived in SA circa 1890 from Gujarat, in the north-western region of the Indian subcontinent. The kindred were consanguineous and several relatives in India were said to have had the condition. (Fig. 1)

The condition remains rare in SA and no other affected families have been identified in any of the populations of this country or in any other region of sub-Saharan Africa.

\section{Affected person I (SB)}

The affected nephew was born in Durban, SA in 1967. He was blind at birth and in infancy, and hyperplasia of the vitreous was diagnosed by an ophthalmologist. At age 5 years he was admitted to the New Horizon School for the Blind in Pietermaritzburg. His performance at this institution was good and he is currently satisfactorily employed as a radio disc jockey. He was diagnosed with osteogenesis imperfecta at the age

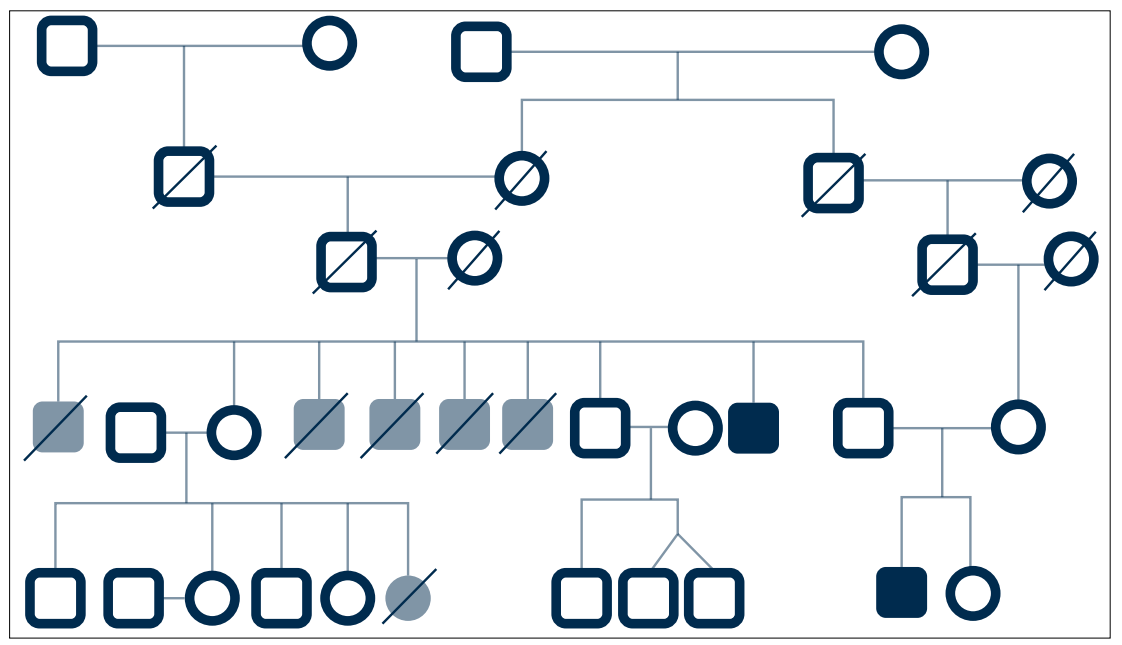

Fig. 1. The pedigree of the affected family. 


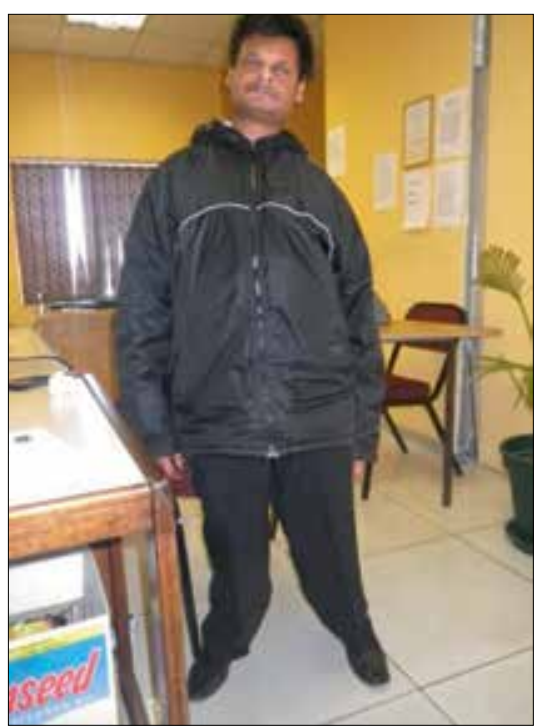

Fig. 2. SB at the age of 45 years is blind and deformities of his legs are apparent.

of 10 years on the basis of radiographic investigations. He recollected having sustained approximately four fractures of his lower limbs, which resulted in limb deformity (Fig. 2).

\section{Affected person II (BB)}

The affected uncle (BB) was born in 1949 in Durban. He recollected that as a young boy, he was blind in his left eye and only had partial sight in his right eye. At 15 years of age, he became completely blind, and when examined at the age of 63 years he had opacities of the globes of both eyes (Fig. 3). Available clinical reports stated that he had seven fractures of his long bones during childhood that resulted in marked limb deformities (Fig. 4). He became chair bound at the age of 25 years.

\section{Affected person III (HB)}

HB was the only affected person in her family. She had unaffected parents and three unaffected male siblings. At 19 years of age, she had sustained more than 10 fractures, was $112 \mathrm{~cm}$ in height, walked with an aid and was mildly visually impaired (Fig. 5). The nature of her visual disability was unknown and has not yet been investigated.

\section{Affected person IV (BA)}

BA was 15 years of age, $110 \mathrm{~cm}$ in height and walked with an aid (Fig. 6). Despite receiving bisphosphonate therapy, her parents gave a history of BA sustaining more than 50 fractures. Her parents were unaffected and she had a younger unaffected male sibling. BA had mild visual impairment of unknown aetiology.

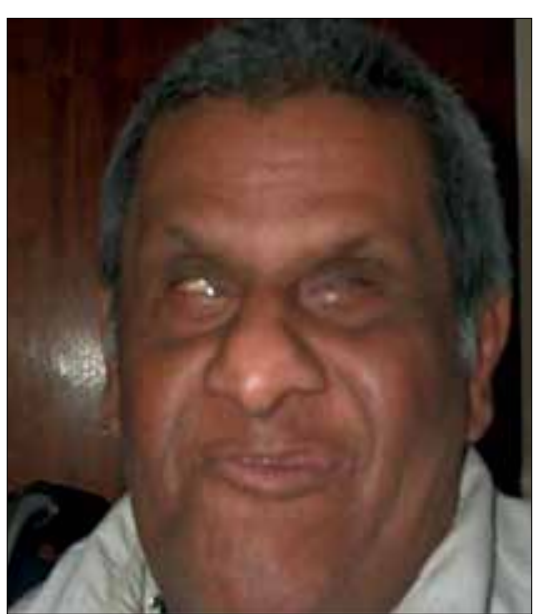

Fig. 3. BB completely blind at age 63 .

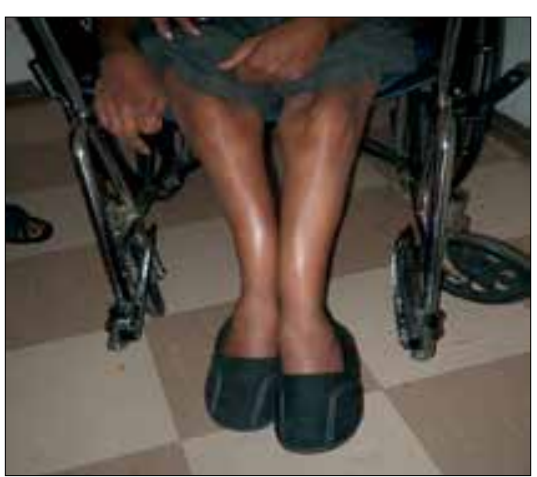

Fig. 4. BB had anterior bowing of his lower legs due to fractures sustained in childhood.

\section{Discussion}

$\mathrm{HB}$ and BA, were born in SA and, although a definite history of consanguinity could not be established, it may be relevant that the progenitors of both individuals hailed from Gujarat province in India. Individuals $\mathrm{HB}$ and BA were not investigated for OPPG, but the possibility that these individuals actually have OPPG cannot be discounted. An attempt by the author to contact their ophthalmologists was unsuccessful. An ophthalmic opinion and further molecular investigations are warranted. The progenitors of all four persons hailed from Gujarat in the north-western region of India. The issue of consanguinity could not be ruled out in the families of $\mathrm{HB}$ and $\mathrm{BA}$, but was confirmed in the family of SB and BB.

The association of the clinical features of ocular involvement and bone fragility were initially described in 1931. ${ }^{[3]}$ Other early reports from 1967 to 1986 concentrated predominantly on the clinical presentation of the syndrome. ${ }^{[2,4-}$ ${ }^{6]}$ In 1955, Meyer described an atypical form of osteogenesis imperfecta using the designation 'Lobstein's disease' and it has since been suggested that this condition might have been OPPG. ${ }^{[7]}$ There have been

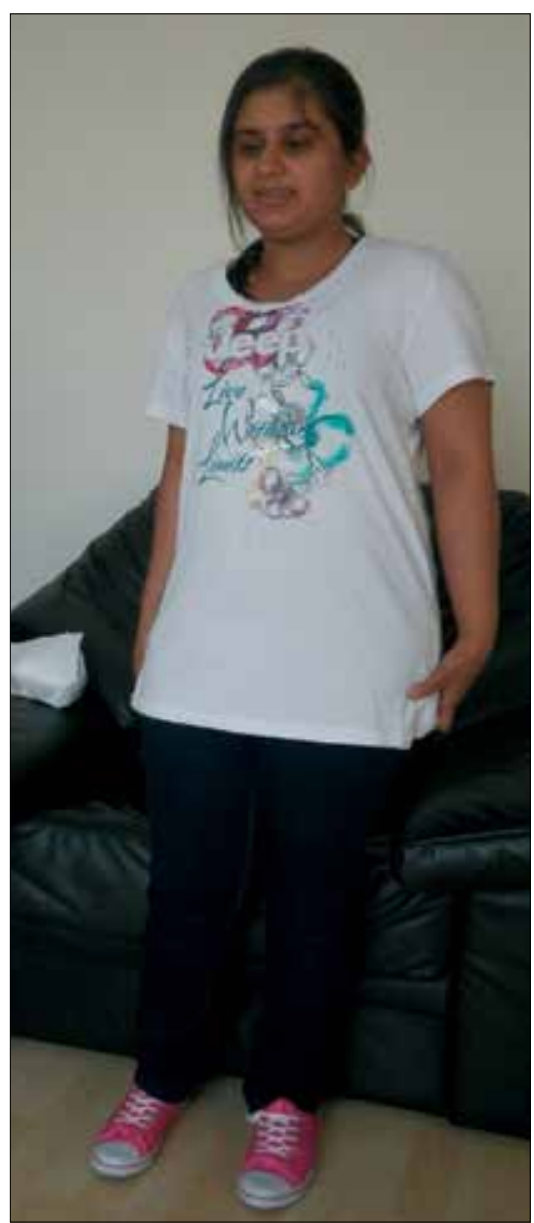

Fig. 5. $H B$ aged 19 years.

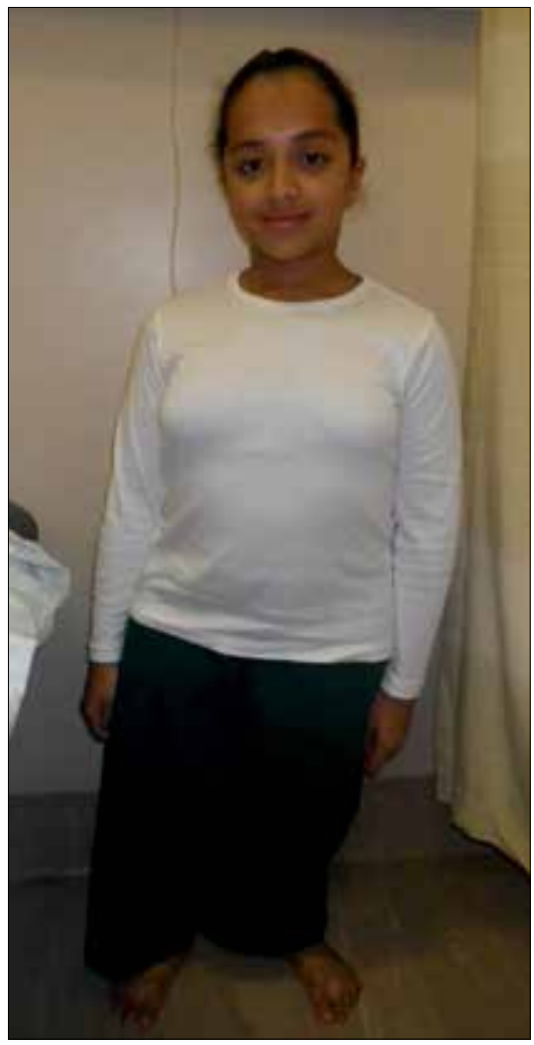

Fig. 6. BA aged 15 years. 
other instances of reported phenotypic confusion between OI and OPPG. ${ }^{[1,2,8]}$ The disorder has been described in association with mild mental retardation ${ }^{[6]}$ and with congenital heart disease. ${ }^{[8]}$ Other inconsistent manifestations of OPPG have included Wormian bones, frontal bossing and hyperextensible joints. ${ }^{[9]}$ Blue sclerae, as in OI, is not a typical feature of OPPG, although this abnormality has been reported in two affected persons. ${ }^{[8]}$

The condition has a wide geographical distribution and it is present in several disparate countries. Following a review of 21 affected persons in eight families, it was suggested that there was a significant gene frequency in Mediterranean countries. ${ }^{[10]}$ In a study conducted in the USA, the clinical and molecular findings were described in 37 probands, and a population incidence of one in two million was estimated. ${ }^{[11]}$ In 2008, a further nine new cases were reported at the Amish Research Clinic in Strasburg. ${ }^{[12]}$ To date, affected individuals have been documented in France, ${ }^{[4,10]} \mathrm{SA},{ }^{[1]}$ Greece, ${ }^{[10,13]}$ India, ${ }^{[14]}$ the USA $^{[11,12]}$ and Tunisia. ${ }^{[15]}$

Gong et al. ${ }^{[16]}$ reported that the OPPG gene was located at chromosome region 11q12-13 on a basis of analysis of 16 DNA samples, including specimens from the SA family. Thereafter, Gong et al. ${ }^{[17]}$ showed that mutations in the low-density lipoprotein receptor-related protein 5 gene (LRP5) caused OPPG in the SA nephew (SB) and his uncle (BB) and other affected families. Using biological material from the studies of Gong et al., ${ }^{[17]}$ the specific mutation in the SA family was identified as 3804delA. ${ }^{[11]}$ The LRP5 gene affects bone mass accrual during growth, and heterozygous carriers of the mutant gene have reduced bone mass when compared with matched controls. ${ }^{[17]}$ These individuals fail to reach an adequate peak bone mass. ${ }^{[12]}$ These findings have been further confirmed by the demonstration that inactivation of LRP5 in osteocytes results in impaired bone size and mass in response to mechanical loading. ${ }^{[18]}$

Although in the majority of cases of OPPG there is loss of function of the LRP5 gene, no mutation has been detected in a significant number of cases. Concepts have evolved and OPPG is now regarded as a member of an overlapping disorder, spondylo-ocular syndrome (SOS), which is also associated with eye abnormalities and vertebral compression fractures. Currently, there is no review specifically addressing the patterns of visual impairment in OPPG and SOS. ${ }^{[19]}$

The general management of OPPG by administration of bisphosphonates and the success thereof have been documented. ${ }^{[20]}$ It has been recommended that patients with OPPG should begin treatment with bisphosphonates in the early years of life. ${ }^{[20]}$ More recently, Arantes et al. ${ }^{[7]}$ provided therapeutic insight into the management of OPPG and supported the rationale for using an osteoanabolic agent. Zhao et al. ${ }^{[18]}$ suggested that increasing LRP5induced signalling in osteoblasts of persons with OPPG may be beneficial to the treatment of osteopaenia and osteoporosis.

\section{Conclusion}

The pedigree of SB and BB showed that six affected members of the family had brittle bones with associated blindness, and these data are consistent with autosomal recessive inheritance. At the time of their diagnosis, genetic counselling, as well as dedicated medical and social care, were the only forms of help that could be offered to these patients and their families. In the SA Indian community, marriages are often consanguineous and it can be postulated that there is a risk that further affected persons could be born in the extended family.

Since the four affected persons depicted in this article had a common ancestry from Gujarat, it seems possible that the determinant gene may be present in significant frequency in SA.

OPPG is similar to OI and SOS in terms of its pathology, and has serious clinical consequences. The improved molecular knowledge of this syndrome over the past decade has facilitated genetic counselling as well as provided successful genetic management options.

\section{References}

1. Beighton P, Winship I, Behari D. The ocular form of osteogenesis imperfecta: A new autosomal recessive syndrome. Clin Genet 1985;28(1):69-75. DOI:10.1111/j.1399-0004.1985.tb01220.x

2. Superti-Furga A, Steinmann B, Perfumo FI. Osteoporosis-pseudoglioma or osteogenesis imperfecta? . Superti-Furga A, Steinmann B, Perfumo FI. Osteoporosis-pseudoglioma
Clin Genet 1986;29(2):184-185. DOI:10.1111/.1399-0004.1986.tb01249.x

3. Pellathy BV. Ablatio retinae und uveitis congenital bei drei Geschwistern. Z Augenheilk 1931;73(45):249-254. DOI:10.1159/000297129

4. Saraux H, Frezal J, Roy C, et al. Pseudogliome et fragilite osseuse hereditaire: A transmission autosomal recessive. Ann Oculist 1967;200:1241-1252.

5. Bianchine JW, Briard-Guillemot ML, Maroteaux P, et al. Generalised osteoporosis with bilateral pseudoglioma-an autosomal recessive disorder of connective tissue: Report of three families - review of the literature. Am J Hum Genet 1972;24:34A.

6. Neuhauser G, Kaveggia EG, Opitz JM. Autosomal recessive syndrome of pseudogliomatous blindness, osteoporosis and mild mental retardation. Clin Genet 1976;9(3):324-332. DOI:10.1111/j.1399-0004.1976.tb01581.x

7. Arantes HP, Barros ER, Kunii I, et al. Teriparatide increase bone mineral density in a man with osteoporosis pseudoglioma. J Bone Miner Res 2011;26(12):2823-2826. DOI:10.1002/jbmr.530

8. Teebi AS, Al-Awadi SA, Marafie MJ, et al. Osteoporosis-pseudoglioma syndrome with congenital heart disease: A new association. J Med Genet 1988;25(1):32-36. DOI:10.1136/jmg.25.1.32

disease: A new association. J Med Genet 1988;25(1):32-36. DOI:10.1136/jmg.25.1.32
9. Heide T. A syndrome of osteogenesis imperfecta, macrocephaly, wormian bones, frontal bossing, Heide T. A syndrome of osteogenesis imperfecta, macrocephaly, wormian bones, frontal bossing,
brachytelephalangy, hyperextensible joints, congenital blindness and oligophrenia 3 sibs (author's brachytelephalangy, hyperextensible joints, congenital blindness and
transl). Klin Padiatr 1981;193(4):334-340. DOI:10.1055/s-2008-1034490

transl). Klin Padiatr 1981;193(4):334-340. DOI:10.1055/s-2008-1034490
10. Frontali M, Chiara S, Dallapiccola B. Osteoporosis-pseudoglioma syndrome: Report of three affected sibs and an overview. Am J Med Genet 1985;22(1):35-47. DOI:10.1002/ajmg.1320220104

11. Ai M, Heeger S, Bartels CF, et al. Clinical and molecular findings in osteoporosis-pseudoglioma syndrome. Am J Hum Genet 2005;77:741-753. DOI:10.1086/497706

12. Streeten EA, McBride D, Puffenberger E, et al. Osteoporosis-pseudoglioma syndrome: Description of 9 new cases and beneficial response to bisphosphonates. Bone 2008;43(3):584-590. DOI:10.1016/j. bone. 2008.04 .020

13. Bartsocas CS, Zeis PM, Elia M, et al. Syndrome of osteoporosis with pseudoglioma. Ann Genet 1982;25(1):61-62.

14. Shaharao V, Shah I, Mishra P, et al. Osteoporosis pseudoglioma syndrome. Indian Pediatr 1999;36(3):313-316.

15. Marques-Pinheiro A, Lavesseur R, Cormier C, et al. Novel LRP5 gene mutation in a patient with osteoporosis-pseudoglioma syndrome. Joint Bone Spine 2010;77(2):151-153. DOI:10.1016/j. spin.2009.11.013

16. Gong Y, Vikkula M, Boon L, et al. Osteoporosis-pseudoglioma syndrome, a disorder affecting skeletal strength and vision, is assigned to chromosome region 11q12-13. Am J Hum Genet 1996;59(1):146151

17. Gong Y, Slee RB, Fukai N, et al. LDL receptor-related protein 5 (LRP5) affects bone accrual and eye development. Cell 2001;107(4):513-523. DOI:10.1016/s0092-8674(01)00571-2

18. Zhao L, Shim JW, Dodge TR, et al. Inactivation of LRP5 in osteocytes reduces Young's modulus and responsiveness to mechanical loading. Bone 2013;54(1):35-43. DOI:10.1016/j.bone.2013.01.033

19. Munns, CF, Fahiminiya, S, Poudel, N, et al. Homozygosity for frameshift mutations in XYLT2 result in a spondylo-ocular syndrome with bone fragility, cataracts, and hearing defects. Am J Hum Genet 2015;96:971-978. DOI:10. 1016/j.ajhg.2015.04.017

20. Bayram F, Tanriverdi F, Kurtoglu S, et al. Effects of 3 years of intravenous pamidronate treatment on bone markers and bone mineral density in a patient with osteoporosis-pseudoglioma syndrome (OPPG). J Pediatr Endocrinol Metab 2006;19(3):275-279. DOI:10.1515/jpem.2006.19.3.275 